\title{
Notas sobre o projeto ético-político profissional: fundamentos, construção e desafios
}

\author{
Notes on the Professional Ethical-Political Project: \\ fundamentals, construction, and challenges
}

\section{Janaína Lopes do Nascimento Duarte*}

\begin{abstract}
Resumo - Na contemporaneidade, o projeto ético-político vem sendo questionado, em parte, devido à dificuldade de compreensão sobre a profissão e seu projeto profissional crítico. Sendo resultado de parte da pesquisa bibliográfica de Doutorado, o presente texto objetiva recuperar os fundamentos desse projeto e seu processo de construção sóciohistórica, ratificando potencialidades e limites. Como ponto de partida, consideramos que projetos profissionais têm limites e possibilidades e que o conhecimento dos seus fundamentos é imprescindível para o fortalecimento da profissão, para a sustentação crítica e para a disputa de direção, diante de outros projetos divergentes postos no cotidiano da luta. Assim, discorremos sobre os fundamentos de um projeto profissional; sobre o processo de construção e trajetória do projeto ético-político e sua articulação com um projeto societário; e sobre os desafios para o exercício e a formação profissionais que incidem sobre o projeto éticopolítico, como também sobre a urgência do seu fortalecimento coletivo como uma conquista histórica da profissão.
\end{abstract}

Palavras-chave: trabalho; projeto profissional; projeto ético-político; Serviço Social.

\begin{abstract}
Nowadays, the ethical-political project has been questioned, in part, due to the difficulty of understanding the profession and its critical professional project. Resulting from part of a Doctorate bibliographical research, this text aims to retrieve the foundations of this project and its socio-historical construction process, ratifying potentialities and limits. As a starting point, we consider that professional projects have both limits and possibilities. The knowledge of their foundations is essential for strengthening professions, establishing critical support, and selecting priorities, in face of other divergent projects appearing in daily struggles. Thus, we discuss the fundamentals of a professional project; the process of construction and trajectory of the ethical-political project and its articulation with a societal project; and the challenges for the professional exercise and training that focus on the ethical-political project and the urgency of its collective strengthening as a historical achievement of the profession.
\end{abstract}

Keywords: work; professional project; ethical-political project; Social Work.

*Doutora em Serviço Social (PPGSS/UFRJ) e professora Adjunta I do Departamento de Serviço Social (SER) da Universidade de Brasília (UnB). Correspondência: Sqn 114, bloco D/apt. 205 - Asa Norte - Brasília/DF. CEP: 70.764-040. Email: <janaduarte@unb.br>. 


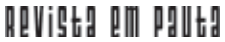

\} NOTAS SOBRE O PROJETO ÉTICO-POLÍTICO PROFISSIONAL - DUARTE, J. L. N. \}

DOI 10.12957/REP.2017.30382

\section{Introdução}

Em tempos de mundialização do capital, ofensiva neoliberal, negação de direitos sociais, ampliação de desigualdades, precarização e intensificação do trabalho, dentre outros processos contemporâneos, como desdobramentos do momento de crise e reestruturação do capitalismo pós-1970, podemos dizer que é necessário reafirmar valores e princípios, fortalecer conquistas históricas e intensificar a luta sociopolítica. Nesse campo o Serviço Social sempre esteve presente de forma combativa, em especial a partir da década de 1960.

Sabemos que até meados da década de 1960, o Serviço Social se constituía com razoável homogeneidade diante das suas concepções de mundo e profissão, da sua direção teórica, ética e política e das suas respostas profissionais concretas. Entretanto, com a entrada dos anos de 1960, o "caráter contraditório dos fenômenos e processos sócio históricos" (NETTO, 1998, p. 129) culminaram com as condições favoráveis para a renovação do Serviço Social, fomentando um processo de questionamento geral e contestação interna, que marcou um contexto de virada crítica na profissão.

Em verdade, o Serviço Social não tem se isentado da luta, da resistência e da disputa cotidianas na sociedade brasileira, especialmente em defesa de interesses que extrapolam a profissão e se vinculam às demandas dos trabalhadores.

Cabe lembrar que o Serviço Social contemporâneo é resultado de um recente processo sócio-histórico de rompimento e reorganização da profissão contra o projeto conservador que dominou sua trajetória até o início da década de 1980, conquistando outra direção social e política a partir do projeto ético-político profissional, especialmente nos anos de 1990, articulado a um projeto de sociedade não capitalista.

Relevante lembrar que, na América Latina, esse processo de renovação adquire contornos específicos, nos quais o Brasil assume um certo protagonismo, particularmente por meio do Movimento de Reconceituação, cobrindo o período específico entre 1965 e 1975. Netto (1998, p. 146) destaca que esse movimento "partilha das mesmas causalidades e características do processo internacional de erosão do Serviço social 'tradicional'". No entanto, ao mesmo tempo, a América Latina apresenta peculiaridades próprias, tais como: a dependência norte-americana e as ditaduras instaladas nos países para conter a efervescência dos movimentos sociais e o "perigo" iminente do comunismo.

No entanto, embora hegemônico (do ponto de vista da direção ético-política conduzida pelas suas entidades organizativas e apoiada na pluralidade da categoria profissional), esse projeto não é exclusivo, mas convive com outros projetos profissionais. Por isso, a luta exige ratificação de princípios e valores, resgate de fundamentos (sempre) e fortalecimento dos projetos societário e profissional radicalmente críticos. 


\section{hevistg an pgutt}

\{ NOTAS SOBRE O PROJETO ÉTICO-POLÍTICO PROFISSIONAL - DUARTE, J. L. N. \}

DOI $10.12957 /$ REP.2017.30382

Na conjuntura atual, o projeto profissional crítico do Serviço Social vem sendo questionado em sua viabilidade e potencialidade, em parte, devido à dificuldade de compreensão sobre a profissão e seu projeto profissional crítico, especialmente no que se refere aos fundamentos, trajetória, limites e desafios desse projeto (que se confunde com os da profissão). Isso pode estimular, no cotidiano profissional, um "sentimento" de impossibilidade, inviabilidade de um projeto de profissão radicalmente contrário à ordem do capital.

Contudo, como compreender a dimensão de um projeto profissional sem saber identificar o que vem a ser um projeto? Quais os fundamentos do projeto ético-profissional do Serviço Social? Como fortalecê-lo em tempos de tantos desafios para a classe trabalhadora e, em particular, para a profissão, sem efetivamente conhecê-lo? Essas são algumas questões que inquietam e circulam entre profissionais e estudantes de Norte a Sul do país ${ }^{1}$, mas que, algumas vezes, não são problematizadas com o rigor e a profundidade necessários, particularmente em tempos de barbárie capitalista e retrocessos sociais no campo do trabalho e da formação profissional em geral.

Nessa perspectiva, como resultado de pesquisa bibliográfica realizada a partir de um recorte dos nossos estudos no Doutorado em Serviço Social (em processo de finalização), o presente texto objetiva recuperar os fundamentos de um projeto de profissão e, nele, o projeto ético-político profissional, bem como seu processo de construção sócio-histórica, ratificando potencialidades e limites, a fim de contribuir com o fortalecimento da profissão e da direção crítica imprimida por tal projeto profissional.

Nosso ponto de partida é considerar que: a) um projeto profissional tem limites e possibilidades que se colocam na contradição dos seus desafios, postos pela complexidade dos processos sociais atuais; e b) o conhecimento a respeito dos fundamentos do projeto ético-político profissional e seu consequente vínculo com um projeto societário anticapitalista se constituem como importantes elementos para a sustentação crítica e a disputa de direção, diante de outros projetos divergentes postos no cotidiano da luta coletiva contemporânea.

Sem o intuito de esgotar o tema, e sobretudo diante das limitações de um texto, organizamos nossa contribuição a esse debate a partir dos seguintes eixos centrais: 1) os fundamentos de um projeto profissional, a fim de elucidar e qualificar teórico-metodologicamente o que é e como se constitui um projeto; 2) o processo de construção e a trajetória do projeto éticopolítico do Serviço Social brasileiro, situando como este se articula a um determinado projeto societário; e 3) considerações finais sobre alguns desafios para o exercício e a formação profissionais que incidem sobre o projeto

\footnotetext{
${ }_{1}$ Aqui cabe também ressaltar nossas observações empíricas, em particular, por meio da supervisão acadêmica de estágio na condição de docente de uma universidade pública federal.
} 
ético-político profissional, bem como a urgência do seu fortalecimento e da construção de um consenso coletivo sobre o mesmo.

\section{Quais os fundamentos que constituem um projeto profissional?}

Para viver, existir, homens e mulheres precisam produzir bens essenciais para suprir suas necessidades em relação direta com a natureza: "o trabalho é um processo entre o homem e a natureza, um processo em que o homem, por sua própria ação, media, regula e controla seu metabolismo com a natureza" (MARX, 1985, p. 149). Na verdade, o homem coloca "em movimento as forças naturais pertencentes a sua corporalidade, braços e pernas, cabeça e mão, a fim de apropriar-se da matéria natural numa forma útil para sua própria vida" (MARX, 1985, p. 149), respondendo às suas necessidades.

É a partir do processo de transformação intencional da natureza que o homem se torna um ser social, distinto dos outros animais, o que somente é possível por meio do trabalho. Explicando melhor: é a partir do trabalho que o homem transforma a natureza, segundo seus interesses, construindo e modificando a si próprio e as suas relações sociais. Ou seja, é o trabalho que permite o salto qualitativo do homem como ser social, distinguindo-o da natureza.

Desta forma, toda a ação humana - e isso é o que nos afasta e distingue dos outros animais da natureza - é resultado da capacidade do homem de projetar/conceber na consciência (prévia ideação) o que almeja e objetiva, construindo materialmente (objetivação ${ }^{2}$ ) aquilo que deseja para alcançar determinada finalidade (fim). Essa finalidade, por sua vez, atenderá a uma necessidade inicialmente posta pela sua relação com a natureza e com os outros homens, por meio do trabalho. É nesse sentido que Marx (1985, p. 149-150 - grifos nossos) pressupõe o trabalho numa forma exclusivamente humana:

Uma aranha executa operações semelhantes às do tecelão, e a abelha envergonha mais de um arquiteto humano com a construção dos favos de suas colméias. Mas o que distingue, de antemão, o pior arquiteto da melhor abelha é que ele construiu o favo em sua cabeça, antes de construí-lo em cera. No fim do processo de trabalho obtém-se um re-sultado que já no início deste existiu na imaginação do trabalhador, e, portanto, idealmente. Ele não apenas efetua uma transformação da forma da matéria natural; realiza, ao mesmo tempo, na matéria natural seu ob-jetivo, que ele sabe que determina, como lei, a espécie e o modo de sua atividade e ao qual tem de subordinar sua vontade. Além do esforço dos órgãos que trabalham, é exigida a vontade orientada a um fim, que se manifesta como atenção durante todo o tempo de trabalho [...].

\footnotetext{
${ }^{2}$ De acordo com Lessa (2002, p. 75), objetivação é a síntese teleologia e causalidade, pois "articula a idealidade da teleologia com a materialidade do real sem que percam suas respectivas essências".
} 
Assim, homens e mulheres têm a capacidade de alterar a natureza e as relações sociais a partir do trabalho, que se constitui como "uma peculiar e exclusiva articulação entre teleologia e causalidade", ou seja, prévia ideação e circunstâncias objetivas, para fins de objetivação de necessidades e interesses humanos, uma vez que "apenas no mundo dos homens a teleologia se faz presente" (LESSA, 2002, p. 70). Isso porque somente os homens detêm a capacidade de antecipar idealmente.

Portanto, o ato de projetar é necessariamente um ato humano. Os seres humanos sempre atuam de forma teleológica ${ }^{3}$, quer dizer, orientados por objetivos e finalidades, o que requer certo grau de consciência para a objetivação, pois "toda processualidade teleologicamente orientada requer alguma consciência que a ponha" (LESSA, 2002, p. 71). Por isso, o homem transforma a realidade a partir de uma finalidade previamente construída, projetada.

Nesses termos, toda ação humana, cuja motivação será sempre um conjunto de necessidades e interesses, implica necessariamente um projeto que se constitui como uma antecipação ideal para alcançar determinada finalidade. Essa exige valores para legitimá-la e a escolha de meios para alcançá-la (NETTO, 2008).

Então, um projeto é resultado da dinâmica teleologia e causal, cuja síntese é a objetivação que determina e é determinada pela relação entre objetividade (materialidade do real, ou seja, condições materiais de produção e reprodução social) e subjetividade (processo de consciência) humana.

Nesse processo, é fundamental que "a subjetividade capture, na medida minimamente necessária para cada objetivação, as determinações do real" (LESSA, 2002, p. 93). Ou seja, isso exige consciência, que é determinada pelas condições materiais de existência e que, por sua vez acionada, passa a interferir tanto nas condições materiais quanto no processo de consciência (revolucionária ou conservadora, a depender dos interesses de classe e das condições sócio-históricas). Aqui estão postas as condições para tecer a história da humanidade, que é construída pelos homens e mulheres de seu tempo, a partir do intercâmbio com a natureza por meio do trabalho ${ }^{4}$.

De acordo com lasi (2011), o movimento da consciência ${ }^{5}$ não é um processo linear, mas é construído por formas que se superam dialeticamente, de modo que o velho traz elementos do novo, que, dessa forma, ainda carrega resquícios do que já foi superado. Logo, não há linearidade,

\footnotetext{
3 "Lukács afirma que a constituição interna de toda posição teleológica é composta por dois momentos: a posição do fim e a busca dos meios" (LESSA, 2002, p. 86).

${ }^{4}$ É um sentido de história materialista, dialético e centrado no trabalho (MARX; ENGELS, 2009), que potencializa a ação humana, na articulação teleologia (objetivação - causalidade - consciência), e conecta às condições materiais de vida.

${ }^{5}$ Particularizando o Serviço Social, é importante salientar que não nascemos assistentes sociais, mas nos tornamos. Isso significa dizer que esse processo é histórico, é diverso na trajetória individual e coletiva de cada um. Por isso, "temos que considerar a necessária temporalidade para gestar seja o profissional assistente social em sua dimensão individual, seja o coletivo da categoria profissional" (SANTOS, 2010, p. 704).
} 


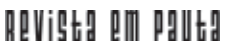

\} NOTAS SOBRE O PROJETO ÉTICO-POLÍTICO PROFISSIONAL - DUARTE, J. L. N. \}

DOI 10.12957/REP.2017.30382

é um processo de saltos, continuidades e rupturas. Esse movimento é determinado pelas condições materiais de existência, ou seja, pela realidade social fundada na ordem do capital, e, consequentemente, na inserção de classe dos indivíduos.

Tal processo se constitui, ao mesmo tempo, como "múltiplo e uno" (IASI, 2011, p. 13): cada indivíduo "transita de certas concepções de mundo até outras, vive subjetivamente a trama de relações que compõe a base material de sua concepção de mundo", ou seja, cada um precisa buscar explicações, construir respostas conscientes sobre a realidade. Por outro lado, a sua condição de classe o situa no campo da universalidade, em que as "diferentes particularidades derivadas do processo próprio de vida de cada um sintetizam (sob algumas condições) um todo que podemos chamar de consciência de classe" (IASI, 2011, p. 13), passível de acontecer em tempos diferentes para cada indivíduo. Em verdade, as condições materiais de existência se colocam no campo da universalidade, do múltiplo, sendo que cada um também construirá (ou não) seu processo de consciência de forma individual; assim, universalidade e singularidade se conectam dialeticamente.

Por isso, um projeto (profissional ou não) não pode se concretizar somente no limite das ideias, da consciência. É necessária sua conexão com a realidade social, suas contradições e relações, sua história e movimento, já que "parte-se dos homens realmente ativos, e com base no seu processo real de vida" (MARX; ENGELS, 2009, p. 31).

A formação da consciência "[...] está em princípio diretamente entrelaçada com a atividade material e o intercâmbio material dos homens" (MARX; ENGELS, 2009, p. 31). Tendo isso em vista, lasi (2011, p. 20) afirma que a alienação se constitui como "a forma de manifestação inicial da consciência", uma vez que todos se inserem em uma sociedade de classe consolidada, a saber, a capitalista. Por isso, não há como se socializar nessa sociedade sem ser pela mediação da alienação ${ }^{6}$.

É oportuno ressaltar que em uma sociedade de classes, a que detém os meios de produção também detém condições de universalizar sua visão de mundo na direção da manutenção da sua dominação: "as ideias da classe dominante são, em todas as épocas, as idéias dominantes, ou seja, a classe que é o poder material dominante da sociedade é, ao mesmo tempo, o seu poder espiritual dominante" (MARX; ENGELS, 2009, p. 67).

Assim, as ideias dominantes têm correspondência com as relações sociais concretas, vividas pelos sujeitos e pelas classes sociais. Essas relações são baseadas na propriedade privada e no assalariamento da força de trabalho, no qual a realização do trabalho não humaniza o indivíduo, mas o

\footnotetext{
${ }^{6}$ Em Ideologia alemã, Marx e Engels (2009, p. 44) afirmam que "a consciência é, pois, logo desde o começo, um produto social, e continuará a sê-lo enquanto existirem homens".
} 
aliena da produção e das suas relações (aqui se firmam as condições do processo de alienação).

Marx (2004) explica a alienação pelo estranhamento que se estabelece por meio do trabalho e do produto deste na relação homem-natureza, homem-humanidade e homem-homem: "[...] a objetivação (do trabalho) como perda do objeto e servidão ao objeto, a apropriação como estranhamento, como alienação" (MARX, 2004, p. 80). Em outras palavras, para o autor, a alienação se expressa em três níveis. O primeiro deles é o chamado "Estranhamento da coisa" (da natureza e da produção): relação do trabaIhador com o produto do trabalho como objeto estranho e poderoso sobre ele. Essa relação acontece, ao mesmo tempo, com o mundo exterior sensível, com os objetos da natureza como um mundo alheio que se lhe defronta hostilmente. O segundo é o "Estranhamento de si" (do próprio ser humano - autoalienação): relação do trabalho com o ato da produção no interior do trabalho, que caracteriza-se a partir da relação do trabalhador com sua própria atividade como uma atividade estranha, não pertencente a ele; a atividade como miséria, independente dele e não pertencente a ele, através da qual ele próprio se coisifica. Por fim, extraída dos dois níveis anteriores, há o "Estranhamento do homem como espécie, gênero humano", pois o indivíduo se afasta do vínculo que o une à espécie, que o universaliza, impedindo que o ser tenha consciência da espécie a que pertence.

Netto $(1981$, p. 75$)$ ressalta que a alienação não constitui em fenômeno exclusivo da sociedade burguesa, mas, no capitalismo, "o fetichismo implica a alienação, realiza uma alienação determinada e não opera compulsoriamente a evicção de formas alienadas mais arcaicas".

Para Mészáros (2006, p. 21), "a alienação do trabalho se expressa como raiz causal de todo o complexo de alienações", ou seja, a materialidade dessas relações na sociedade capitalista se espraia para todo o universo de socialização dos indivíduos, constituindo, validando e sedimentando sua forma de pensar, viver e agir sobre o mundo, e incidindo também sobre seus projetos individuais e coletivos.

Vinculada à problemática da alienação, encontramos as formulações sobre o fetichismo da mercadoria, que, em Marx (1985), ganha potencialidade crítica para compreender as particularidades da sociedade capitalista contemporânea. Seu ponto de partida é a indagação de que a produção mercantil dominante, instaurada sob fundamentos essencialmente sociais, de fato obscurece e escamoteia tais fundamentos, conduzindo o produto do trabalho, sob a forma de mercadoria, a uma aparência misteriosa. O autor revela:

[...] Não é mais nada que determinada relação social entre os próprios homens que para eles aqui assume a forma fantasmagórica de uma relação entre coisas [...] Isso eu chamo fetichismo que adere aos produtos de trabalho tão logo são produzidos como mercadorias, e que, por isso, é inseparável da produção de mercadorias. (MARX, 1985, p. 71 - grifos nossos). 


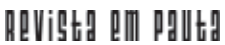

\} NOTAS SOBRE O PROJETO ÉTICO-POLÍTICO PROFISSIONAL - DUARTE, J. L. N. \}

DOI $10.12957 /$ REP.2017.30382

Esse mecanismo do fetichismo se universaliza e passa a dominar todas as relações sociais como coisas: "Seu próprio movimento social [da mercadoria] possui, para eles [indivíduos], a forma de um movimento de coisas, sob cujo controle se encontram, em vez de controlá-las" (MARX, 1985, p. 73). É o que redimensiona e amplia o processo da alienação na ordem burguesa.

Por isso, Netto (1981, p. 56) afirma que, "nas condições desta sociedade, o trabalho não é a objetivação pela qual o ser genérico se realiza: é uma objetivação que o perde, que o aniquila". Por conseguinte, "a alienação é uma forma específica e condicionada de objetivação" no capitalismo, no qual tudo se reduz ao lucro, à mercadoria, pois, "produzindo-as, produz-se a si mesmo e ao produtor como mercadorias. Trata-se de uma forma histórica do trabalho: o trabalho alienado"7 (NETTO, 1981, p. 57).

A partir do fetichismo, a sociedade capitalista (inteiramente mercantilizada) adquire uma forma nova, determinada e particular de alienação profunda, que escraviza os indivíduos tanto pelas condições objetivas da sua inserção de classe no processo produtivo, quanto pelas condições subjetivas de internalização psicossocial, decorrentes da mesma inserção e das suas relações sociais. A essa forma qualitativamente diferente e peculiar da alienação na sociedade capitalista, em que o fenômeno do fetichismo se intensifica, se complexifica e se universaliza, extrapolando a esfera da produção, chamamos reificação ${ }^{8}$.

No entanto, ao mesmo tempo em que estão postas as condições de uma sociedade alienante, é possível negá-la. Tal fato se dá porque, segundo Mészáros (2006, p. 166), a atividade alienada não produz somente a alienação, mas também produz, contraditoriamente, a "consciência de ser alienado", uma vez que "não somente contradiz a ideia de uma totalidade alienada inerte, como também indica o aparecimento de uma necessidade de superação da alienação". Isso significa afirmar que o homem é, ao mesmo tempo, produto e negador dessa sociedade alienada. É nesses termos que o Serviço Social, em determinadas condições sócio-históricas, constrói sua "virada", renova-se e aponta caminhos para a construção de projeto crítico de profissão e sociedade.

Assim, em determinadas condições, a vivência da contradição entre valores assumidos e novas relações vividas pode gerar uma inicial superação da alienação, particularmente vivida coletivamente: "vislumbra-se a possibilidade de não apenas se revoltar contra as relações predeterminadas, mas alterá-las. Questiona-se o caráter natural dessas relações e sua inevi-

\footnotetext{
7 É importante lembrar que, na sociedade burguesa, a alienação se estabelece pelo trabalho assalariado que submete o desenvolvimento do homem a tais condições e formas cada vez mais perversas.

${ }^{8}$ Netto $(1981$, p. 11) afirma que "pensar a problemática da reificação é, necessariamente, pensar a problemática da alienação e do fetichismo", defendendo que a manutenção funcional do capitalismo tardio tem seu elemento axial na reificação das relações sociais. É nesse contexto sócio-histórico que o Serviço Social se insere como profissão, a partir do capitalismo monopolista, e que posteriormente constrói um projeto crítico de profissão.
} 


\section{hevistg an pgutt}

\{ NOTAS SOBRE O PROJETO ÉTICO-POLÍTICO PROFISSIONAL - DUARTE, J. L. N. \}

DOI 10.12957/REP.2017.30382

tabilidade" (IASI, 2011, p. 29-30). É condição fundamental conceber-se "diante da tarefa histórica da superação desta ordem" (IASI, 2011, p. 32), ou seja, a busca pela transformação das condições de vida e de trabalho para além do capitalismo deve ser um horizonte a perseguir, constituindose como fim. Por isso, podemos dizer que os projetos (individuais e/ou profissionais) se conectam a projetos coletivos mais amplos, projetos de sociedade.

Contudo, esse processo é dinâmico, o que significa que o processo de consciência envolve continuidades e rupturas e, sobretudo, não se caracteriza como uma evolução. Constitui-se como um processo dialético entre diferentes sujeitos que apreendem o real de formas diversas, pois estão inseridos de maneiras distintas na sociabilidade do capital e, assim, podem ou não fazer a transição da alienação para outro estágio de consciência.

É preciso compreender com profundidade as relações para além de seu tempo e espaço, ir para além da sua classe e tomar como sua a história da classe e da humanidade. O processo de transformação deve ser necessariamente social e produto da transição desse modo de produção para outro, pois, como afirma Marx (1985, p. 76):

A figura do processo social da vida, isto é, do processo da produção material, apenas se desprenderá do seu místico véu nebuloso quando, como produto de homens livremente socializados, ela ficar sob seu controle consciente e planejado. Para tanto, porém, se requer uma base material da sociedade ou uma série de condições materiais de existência, que, por sua vez, são o produto natural de uma evolução histórica longa e penosa.

Destarte, a transformação da consciência não deve ser considerada como um processo por fora da luta política e da materialidade onde esta se insere. "É ao mesmo tempo um produto da transformação material da sociedade e um meio político de alcançar tal transformação" (IASI, 2011, p. 43). Portanto, a construção de um projeto crítico à ordem vigente constituise como um processo e exige um projeto societário genuinamente distinto do capitalismo e que seja veiculado pelos trabalhadores, única classe capaz e com reais interesses de operar uma transformação revolucionária a partir de um novo patamar de consciência humana.

Importante lembrar que os projetos societários são projetos coletivos que se constituem em propostas para o conjunto da sociedade, caracterizando-se, simultaneamente, como projetos de classe, uma vez que têm sempre em seu núcleo a marca da classe social a cujos interesses essenciais atendem, envolvendo uma dimensão política (NETTO, 2008).

A construção de projetos coletivos (sejam de caráter societário ou até mesmo profissionais) exige uma efetiva tomada de consciência para ser desenvolvido, tal como apontado nas linhas anteriores. É a partir desse solo, portanto, que podemos conceber o projeto ético-político do Serviço Social 


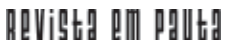

\} NOTAS SOBRE O PROJETO ÉTICO-POLITICO PROFISSIONAL - DUARTE, J. L. N. \}

DOI $10.12957 /$ REP.2017.30382

como um processo localizado na sociedade capitalista alienada/fetichizada/ reificada, o qual se compõe como parte da totalidade da profissão, constituindo-se a partir dos limites e das possibilidades que a realidade (im)põe.

$\mathrm{Na}$ direção do debate estimulado nesse item, e a partir de todos os fundamentos aqui articulados, é possível sustentar a existência de projetos profissionais como projetos coletivos, diretamente vinculados a um determinado projeto de sociedade, em todas as áreas profissionais. No que se refere ao Serviço Social, é possível também afirmar a convivência entre projetos profissionais; contudo, até a atualidade, o projeto crítico à ordem capitalista, vinculado aos interesses do trabalho, ainda vem dando a direção ética e política da profissão, em especial no campo legal e na organização política, e ainda determinando as diretrizes da formação e do exercício profissionais, apesar dos imensos limites atuais.

Por isso, os projetos profissionais se articulam a um conjunto de concepções e valores, elegidos pelas profissões, que extrapolam normatizações e códigos de ética. Netto (2008, p. 148) já atentava para a "contemporânea designação de projetos profissionais como ético-políticos", uma vez que os mesmos requerem sempre uma fundamentação de valores de natureza ética, mas que não se esgota em seus códigos. Além disso, apresentam elementos éticos que ultrapassam as normativas e/ou prescrições de direitos e deveres e envolvem as opções teóricas, ideológicas e políticas dos profissionais. Ou seja, "uma indicação ética só adquire efetividade histórico-concreta quando se combina com uma direção político profissional" (NETTO, 2008, p. 148).

É a partir desses fundamentos que enfatizaremos e resgataremos o projeto ético-político profissional do Serviço Social (contrário ao projeto conservador que persiste na profissão, em especial no campo das instituições), na condição de projeto coletivo crítico ao capitalismo, construído por assistentes sociais - também partícipes da classe trabalhadora -, no qual o processo de construção se vincula a um projeto societário anticapitalista.

Nesses tempos, consideramos relevante atentar que: a) a ação humana implica sempre um projeto, resultado da dinâmica entre teleologia e causalidades, o que gera uma nova objetividade social e desafios a esta; b) os projetos se constituem como individuais e coletivos, sempre articulados a um projeto de sociedade, portanto, com direção social e política orientada por uma condição de classe; e c) os projetos se constituem como parte de uma totalidade, no caso do Serviço Social, como parte do complexo dinâmico e contraditório da profissão, no qual incidem várias determinações da realidade. 


\section{Construção e trajetória do projeto ético-político do Serviço Social brasileiro}

O projeto ético-político profissional tem sua construção e emergência determinadas pelo processo sócio-histórico que articula aspectos (autoimplicados) tanto internos quanto externos ao Serviço Social. Podemos citar alguns desses aspectos: o acúmulo de reflexões que emergem com a Reconceituação ${ }^{9}$ do Serviço Social na América Latina e no Brasil (1960 e 1970) e com a crise do Serviço Social "tradicional"10; as lutas sociais pela redemocratização do país entre 1980 e 1990; a organização política da categoria profissional, por meio da ação das suas entidades representativas ${ }^{11}$; e a incorporação de vertentes críticas inspiradas na tradição marxista, compatíveis com a ruptura ao conservadorismo profissional (NETTO, 2008).

Esse é o caldo cultural que alicerça o projeto ético-político e movimenta a profissão e a sociedade a partir dos anos de 1980. Questionamentos internos à profissão alteravam decisivamente sua forma de pensar o mundo, o homem, o Serviço Social e a sociedade capitalista, coincidindo com o processo de desmonte da Ditadura e com a ampla mobilização da classe trabalhadora em torno de demandas democráticas e populares reprimidas, no qual o próprio assistente social passa a se reconhecer como parte das camadas trabalhadoras. Essa dinâmica fornece algumas condições para a alteração do processo de consciência e, consequentemente, para a incorporação do Serviço Social brasileiro no movimento mais amplo de renovação da profissão (ainda que com limites concretos aqui no Brasil).

Netto (2008) afirma que esse processo não foi homogêneo no corpo profissional, mas que segmentos mais dinâmicos da categoria se aliaram ao movimento dos trabalhadores e, rompendo com a hegemonia do conservadorismo, conseguiram instaurar o pluralismo político na profissão, que contribuiu para o redimensionamento do processo de organização profissional, inserindo suas entidades no marco do movimento dos trabalhadores no Brasil. Nesse sentido, Abramides e Cabral (2009, p. 72) analisam que:

\footnotetext{
${ }_{9}^{9}$ Ortiz (2010) ressalta que a chamada Reconceituação imbuiu-se das questões e processos comumente presentes entre todos os países latino-americanos em um determinado momento datado historicamente, que vai de 1965 a 1975, em razão particularmente da ascensão de regimes ditatoriais na América Latina, bem como diante da própria heterogeneidade do movimento.

${ }^{10}$ Segundo Netto (2005), o Serviço Social tradicional se constitui na prática empirista, reiterativa, paliativa e burocratizada que os profissionais realizavam efetivamente na América Latina, orientada por uma ética-liberal burguesa, de um ponto de vista funcionalista, que visava enfrentar as incidências psicossociais da questão social sobre indivíduos e grupos a partir da ordenação capitalista da vida social como um dado factual ineliminável. ${ }^{11}$ Dentre as entidades representativas da profissão no Brasil, destacamos o então Conselho Federal de Assistentes Sociais (CFAS) e seus Conselhos Regionais (Cras), bem como a Associação Brasileira de Ensino de Serviço Social (ABESS), hoje respectivamente CFESS, Cress e Abepss. Na América Latina, destacamos a articulação de entidades como a Associação Latino Americana de Escolas de Trabalho Social (Alaets), fundada em 1965, no Peru, e o Centro de Estudos Latino Americano de Trabalho Social (Celats).
} 
A inserção das associações, sindicatos, CENEAS ${ }^{12} /$ ANAS $^{13}$ no mo-vimento sindical mais geral dos trabalhadores possibilitou: aprofundar a consciência da categoria profissional de sua condição de trabalhador assalariado, de seu compromisso com a classe trabalhadora, a vinculação com as lutas concretas da categoria e do conjunto dos trabalhadores, o que imprimiu uma solidariedade de classes - apoio financeiro e político aos fundos de greve das categorias em luta, à luta pela volta dos sindicalistas cassados pela ditadura; participação em greves gerais no país. De outro lado se inseriu na articulação das categorias profissionais de nível universitário na discussão e implantação da nova estrutura sindical aprovada no II Congresso da CUT em 1986.

Dadas as condições objetivas, a conjuntura se revelava como favorável à disputa entre projetos societários e profissionais distintos, permitindo a emergência de um novo projeto profissional, afinado à classe trabalhadora.

Outro aspecto importante foi a legitimação da profissão no âmbito acadêmico, com a produção de conhecimentos a partir da área de Serviço Social, estimulada pelos espaços de pós-graduação. Os resultados começaram a germinar a partir dos anos de 1970, gerando (ainda que de maneira desigual) uma massa crítica considerável que permitiu a interlocução com as Ciências Sociais e outras áreas do saber (Educação, Filosofia, dentre outros). Além disso, instaurou "um pluralismo que permitiu a incidência de concepções teóricas e metodológicas sintonizadas com os projetos societários das massas trabalhadoras" (NETTO, 2008, p. 152), arejando e diversificando as possibilidades de análises e aprofundamentos críticos no Serviço Social.

Também ganhou peso a reflexão sobre a formação, especialmente com a reforma curricular de 1982, com amplo debate. Entretanto, sob a influência da "aproximação enviesada à tradição marxista" (por exemplo, por meio de manuais e não diretamente na obra de Marx) e marcado pelo forte perfil militante e pela perspectiva do agente da transformação social (apesar da sua considerável importância para a formação profissional), este currículo de 1982 passa por um novo processo de renovação em 1996, com a aprovação das Diretrizes Curriculares da (agora) Abepss, que: "[...] tentará superar as lacunas e, ao mesmo tempo, garantir os ganhos de 1982, através da afirmação da direção social estratégica que deve atravessar o exercício e a formação profissional" (GUERRA; ORTIZ, 2009, p. 130).

Tendo isso em vista, a direção tomada se voltou para a adequação da formação às condições postas pelo processo de fim da Ditadura, com o enfrentamento da questão social em patamares diferenciados, e pelas

\footnotetext{
${ }_{12}$ A Comissão Executiva Nacional de Entidades Sindicais de Assistentes Sociais (Ceneas) vigorou no período de 1979 a 1983, e, juntamente com a Anas, contribuiu com a articulação de lutas políticas específicas da categoria às lutas mais amplas, afirmando o compromisso com a classe trabalhadora e a luta anticapitalista.

${ }^{13}$ Cabe considerar a importância da Associação Nacional dos Assistentes Sociais (Anas), de 1983 a 1992 , que teve um destacado papel político na direção e centralização das lutas sindicais e políticas dos assistentes sociais.
} 
exigências e necessidades intelectuais do coletivo de profissionais que refletia sobre a realidade nos espaços de pós-graduações emergentes. Tal contexto exigia um novo profissional, com um novo perfil: "[...] capaz de responder, com eficácia e competência, às demandas tradicionais e às demandas emergentes na sociedade brasileira [...]" (NETTO, 2008, p. 153 - grifos do autor).

Foi a partir de uma nova perspectiva de profissão e de profissional, esta resultante do acúmulo teórico e político proporcionado pela renovação do Serviço Social, em especial pela sua vertente de 'ruptura', que se tornou possível a construção dos eixos norteadores do currículo aprovado na XXI Convenção Nacional de Ensino de Serviço Social, promovida pela ABESS em 1979, e, posteriormente, formalizado em 1982 pelo Ministério da Educação. (GUERRA; ORTIZ, 2009, p. 130).

Soma-se a isso o restabelecimento da democracia política, que carregava a garantia de direitos civis e sociais, e a presença política da profissão na sociedade, exigindo um assistente social distinto daquele pautado pelo conservadorismo, que plenamente se adequava ao período ditatorial.

Para lamamoto (2007, p. 223), esse foi o contexto que possibilitou "um amplo movimento de renovação crítica do Serviço Social", impondo alterações nos âmbitos do ensino, da pesquisa, da organização política dos assistentes sociais e do exercício profissional (ainda que de forma heterogênea).

Cabe ressaltar que um relevante momento de condensação crítica do Serviço Social foi o III Congresso Brasileiro de Assistentes Sociais (CBAS), realizado em 1979 e conhecido como o "Congresso da Virada". De fato, o III CBAS constituiu-se como um "divisor de águas" na trajetória histórica dos congressos e da própria profissão, pois o debate político travado, as posições públicas assumidas coletivamente na defesa dos interesses imediatos e históricos dos trabalhadores e no reconhecimento pelos profissionais da condição de partícipe da classe trabalhadora, em especial pela relação de assalariamento, estabelecem as bases da contestação presente neste CBAS e no processo geral de renovação da profissão (GUERRA; ORTIZ, 2009).

É, portanto, nesse solo histórico que o projeto ético-político do Serviço Social se constitui como um projeto profissional, a partir dos anos de 1990, sendo construído pela respectiva categoria a partir da sua organização, que, nos termos de Netto (2008, p. 144),

[...] apresenta a auto-imagem da profissão, elege valores que a legitimam socialmente, delimita e prioriza objetivos e funções, formula requisitos (técnicos, institucionais e práticos) para seu exercício, prescreve normas para o comportamento dos profissionais e estabelece balizas de sua relação com os usuários de seus serviços, com as outras profissões e com as organizações e instituições sociais privadas e públicas.

Nunca é demasiado afirmar que esse projeto baliza e direciona o exercício profissional, suas relações e a formação acadêmica, sendo reco- 


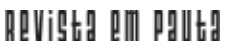

\} NOTAS SOBRE O PROJETO ÉTICO-POLÍTICO PROFISSIONAL - DUARTE, J. L. N. \}

DOI 10.12957/REP.2017.30382

nhecido no coletivo da profissão de Serviço Social. Ou seja: "estabelece um norte, quanto à forma de operar o trabalho cotidiano, impregnando-o de interesses da coletividade, como momento de afirmação da teleologia e da liberdade da práxis social" (IAMAMOTO, 2007, p. 227 - grifos nossos), cuja finalidade central é a articulação da profissão à luta da classe trabaIhadora para a construção de uma sociedade que efetivamente emancipe o homem.

O referido projeto perpassa e concretiza-se, do ponto de vista legal, no Código de Ética (1993), na Lei de Regulamentação da Profissão (Lei no 8.662/1993), nas atuais Diretrizes Curriculares da Formação Profissional (1996), na Política de Estágio Supervisionado (2010), na Lei das 30 horas (Lei $\left.\mathrm{n}^{\mathrm{o}} 12.317 / 2010^{14}\right)^{15}$ e em vários documentos e legislações não específicas. Nestas, a profissão teve participação ativa no processo de elaboração para a garantia de direitos, tais como o Estatuto da Criança e do Adolescente (ECA), a Lei Orgânica da Assistência Social (Loas), dentre outros. Todas essas foram ações concretas que fortalecem a direção política da profissão, contrária à ordem do capital. Assim, esse conjunto contribui e compõe um "alicerce" sólido e progressista para o Serviço Social, resultado da luta da categoria profissional aliada à luta mais ampla da classe trabalhadora.

É possível também afirmar que esse projeto caracteriza uma mudança na direção social estratégica da profissão, particularmente com relação à defesa de princípios fundamentais que configuram sua estrutura básica enquanto projeto profissional, articulando-se a um conjunto de valores éticos e políticos emancipatórios:

A liberdade como valor ético central; a defesa dos direitos humanos; a ampliação e consolidação da cidadania; o aprofundamento da democracia; o posicionamento em favor da eqüidade e justiça social; a eliminação de todas as formas de preconceito e o respeito à diversidade; a garantia do pluralismo; o compromisso com a qualidade dos serviços prestados; a articulação com outras categorias profissionais e a luta pela construção de uma nova ordem societária. (CFESS, 2003, p. 9-11 - grifos nossos).

Cabe lembrar que os projetos profissionais se conectam de forma indissociável a interesses mais gerais da sociedade, por meio da sua vinculação e compromisso com um projeto societário. No caso do Serviço Social, o projeto ético-político se vincula a um projeto de sociedade transformador, já que suas acepções e valores o aproximam de projeções sócio-históricas de ruptura com a ordem vigente. Nesses termos, um projeto profissional

\footnotetext{
${ }^{14} \mathrm{O}$ art. 5o-A acrescenta à Lei ${ }^{\circ}{ }^{\circ} 8.662 / 1993$ que a duração da jornada de trabalho do assistente social é de 30 horas semanais, sendo vedada a redução de salário (BRASIL, 2010). Embora seja uma conquista da categoria profissional, até os dias atuais é objeto de luta e mobilização pela sua garantia efetiva.

${ }_{15}$ Tanto a PNE quanto a Lei das $30 \mathrm{~h}$ se constituem como expressões da luta por direitos: 1) uma voltada para o campo da formação crítica e qualificada, por meio do estágio supervisionado afinado com as diretrizes de 1996; e 2) a outra dimensionada no campo dos direitos trabalhistas, a partir da redução da carga horária no exercício profissional do assistente social.
} 
também tem uma ineliminável dimensão política, já que se situa no campo das "lutas pela hegemonia na sociedade e na profissão" (IAMAMOTO, 2007, p. 223), articulando-se a um conjunto de concepções teóricas, éticas, políticas e ideológicas.

Entretanto, isso não significa dizer que o projeto ético-político constitui-se como um projeto exclusivo, pois "o sujeito coletivo que constrói o projeto profissional constitui um universo heterogêneo" (NETTO, 2008, p. 145). Esse universo é composto inevitavelmente por indivíduos diferentes (origens, inserções, expectativas sociais, condições de classe, preferências teóricas, políticas e ideológicas distintas, processos de consciência diferentes, entre outros aspectos), o que configura um espaço plural ${ }^{16}$, de tensões e lutas.

Por isso, o projeto ético-político pode conviver com o pluralismo de ideias e posturas teórico-metodológicas e ético-políticas no cotidiano profissional, abrindo espaço para o debate, o confronto e a disputa de ideias e projetos individuais, profissionais e societários. De acordo com Netto (2008, p. 145 - grifo nosso), a "afirmação e consolidação de um projeto profissional em seu próprio interior não suprime as divergências e contradições [...] mesmo um projeto que conquiste hegemonia nunca será exclusivo".

Por outro lado, podemos considerá-lo (ainda) hegemônico no Serviço Social, uma vez que se firma sobre uma diversidade de outros e consolida uma direção social e política ao exercício e à formação profissional, construindo uma espécie de "imagem ideal da profissão" (NETTO, 2008), que envolve aspectos teóricos, políticos, organizativos e jurídico-legais. Acima de tudo, tal projeto crítico estabelece a direção da profissão em vários aspectos, mesmo que, na atualidade, confronte-se e dispute (com outros projetos) espaço no cotidiano da formação e do exercício profissionais.

Em face do exposto, podemos inferir que esse projeto está em processo, afirmando e reafirmando princípios e valores no seu cotidiano, vivenciando uma luta de ideias e posturas em que o assistente social pode fortalecê-lo, ou não, de acordo com suas ações, sua apreensão ídeo-política e teórico-metodológica, bem como conforme suas condições objetivas traçadas pelo capitalismo contemporâneo.

Também é relevante destacar que os projetos profissionais, como é o caso do projeto ético-político, apresentam-se como estruturas dinâmicas (NETTO, 2008) que se renovam e se transformam ao responder às alterações nas necessidades e demandas sociais, às transformações sócio-históricas e culturais, ao desenvolvimento teórico e prático da profissão e às mudanças no seu corpo profissional.

O cenário atual acirra contradições (novas e antigas), e o projeto ético-político do Serviço Social se confronta com a face presente do projeto

\footnotetext{
${ }^{16}$ Para Netto (2008), o pluralismo é um elemento que deve ser respeitado, mas não deve ser confundido com tolerância liberal para com o ecletismo, assim como não pode inibir a luta de ideias e nem pode cancelar o respeito às hegemonias legitimamente conquistadas.
} 


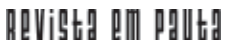

\} NOTAS SOBRE O PROJETO ÉTICO-POLÍTICO PROFISSIONAL - DUARTE, J. L. N. \}

DOI 10.12957/REP.2017.30382

dominante, o projeto neoliberal. Nessa perspectiva, "dar vida" a esse projeto crítico à ordem e fortalecê-lo exige o desafio da interpretação contemporânea do movimento das classes, da relação entre o Estado e a sociedade, da forma como esses processos incidem sobre o cotidiano profissional, bem como exigem ainda a diária construção de ações coletivas combativas. Dessa forma, "sem considerar essa dinâmica histórica, ao se falar em projetos societários e profissionais, pode-se cair na armadilha de um discurso que proclama valores radicalmente humanistas, mas não elucida suas bases concretas" (IAMAMOTO, 2007, p. 229).

Então, para o debate e a compreensão dos processos sociais contemporâneos que incidem diretamente sob o projeto de profissão ainda hegemônico no Serviço Social a partir de 1990, é necessário considerar que tais processos se particularizam no conjunto articulado da profissão, ou seja, recaem dialeticamente sobre o exercício e a formação profissionais na atualidade, acarretando desafios ao projeto ético-político.

\section{Considerações finais: alguns fundamentos do trabalho profissional, desafios e a perspectiva de fortalecimento do projeto ético-político profissional}

O Serviço Social vivencia e é determinado, no cotidiano ${ }^{17}$ profissional, pelas alterações significativas do seu tempo histórico. Ao longo da história da profissão, o confronto entre classes e projetos societários sempre esteve presente, determinando demandas e respostas profissionais. A partir da renovação do Serviço Social, o confronto com o projeto de sociedade da ordem capitalista fica mais evidente, trazendo para o cotidiano profissional de um trabalhador assalariado novas contradições e necessidades. Não desconsiderando tudo isso, neste texto, em particular, enfatizamos a contemporaneidade da profissão, e por isso aqui chamaremos a atenção para o tempo atual com a reorganização do capital, os seus desdobramentos na vida cotidiana e no conjunto exercício/formação profissionais.

Atualmente, é o binômio crise e reestruturação capitalista que vem imprimindo novos contornos às condições objetivas e subjetivas do seu trabalho, às necessidades sociais dos usuários e às demandas e requisições profissionais, com incidências contundentes nas respostas da profissão. Logo,

Trilhar da análise da profissão ao seu efetivo exercício supõe articular projeto de profissão e trabalho assalariado; ou o exercício da profissão

\footnotetext{
17 Netto (2007, p. 66), a partir de Lukács, afirma que, "enquanto espaço-tempo de constituição, produção e reprodução do ser social, a vida cotidiana é ineliminável", mas sua estrutura é distinta em cada sociedade. O autor destaca também os componentes ontológico-estruturais da vida cotidiana: "a heterogeneidade, a imediaticidade e a superficialidade extensiva" (NETTO, 2007, p. 67).
} 
nas condições sociais concretas de sua realização mediada pelo estatuto assalariado e por projeções sociais coletivas profissionais integradas ao horizonte coletivo das classes trabalhadoras na luta pela conquista e ampliação de direitos como estratégia contra-hegemônica. (IAMAMOTO, 2007, p. 230 - grifos nossos).

Ao inserir a profissão no conjunto de determinações sociais na sociedade capitalista contemporânea, é necessário situá-la a partir da sua condição assalariada. Essa condição promove a inserção em processos alienantes e reificados, por meio da venda da sua força de trabalho a empregadores diversos, como Estado, empresas privadas, ONGs, entidades filantrópicas, organismos de representação política e outros, como uma mercadoria que tem valor de uso. Isso porque responde à determinada necessidade social a partir do capitalismo em seu estágio monopolista.

Portanto, a condição assalariada preconiza uma gama de implicações no processo de autonomia relativa para o projeto ético-político profissional, já que envolve, necessariamente, "a incorporação de parâmetros institucionais e trabalhistas que regulam as relações de trabalho [...] e estabelecem as condições em que o trabalho se realiza" (IAMAMOTO, 2007, p. 218). Ou seja, a instituição acaba por estabelecer: intensidade, jornada de trabalho, salário e metas a cumprir. Além disso, particulariza funções e atribuições profissionais, prioridades e demandas a serem atendidas, recursos, instrumentos e técnicas, bem como as condições gerais de sua realização, ainda que a autonomia relativa do profissional seja uma realidade posta nas instituições. Nesse terreno, encontra-se outro vetor importante: a disputa pelas necessidades sociais dos sujeitos usuários do Serviço Social, que, por meio das lutas e tensões de poder, são incorporadas como demandas profissionais no espaço da instituição.

$\mathrm{Na}$ contemporaneidade, a tendência destrutiva no mundo do trabalho atinge e desafia o exercício profissional do assistente social, que tem na flexibilização uma forma de precarização e intensificação do trabalho. Segundo Guerra (2010), a precarização do exercício profissional se expressa em diversas dimensões: desregulamentação do trabalho, mudanças na legislação trabalhista, subcontratação, diferentes formas de contração e vínculos cada vez mais precários e instáveis, terceirização, emprego temporário, informalidade, jornadas de trabalho e salários flexíveis, multifuncionalidade, polivalência e desespecialização.

Comparece hoje nos espaços laborais do assistente social o crescente aumento de profissionais que possuem mais de um vínculo de trabalho, o que caracteriza o pluriemprego, bem como se observa a inserção socioprofissional em duas ou mais políticas sociais, rotatividade no emprego, instabilidade e insegurança, jornada de trabalho extensa (cumpre carga horária de mais de dez horas de trabalho), além do sobretrabalho ao qual a mulher encontra-se submetida. (GUERRA, 2010, p. 720). 


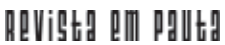

\} NOTAS SOBRE O PROJETO ÉTICO-POLÍTICO PROFISSIONAL - DUARTE, J. L. N. \}

DOI $10.12957 /$ REP.2017.30382

Agregam-se a essas questões/reflexões a dinâmica do momento contrarrevolucionário atual de fragmentação e fragilização da organização política da classe trabalhadora. Essa fragilização tem, na intensificação e na maior exploração do trabalho, bem como na redução e violação de direitos sociais e trabalhistas (dos usuários e dos próprios assistentes sociais enquanto trabalhadores), expressões que entorpecem o sujeito assistente social (individual e coletivo), dificultando sua tomada de consciência e consequente mobilização e resistência, além de desencadear um processo de desgaste e adoecimento $^{18}$.

Tudo isso ocorre porque, enquanto trabalhador que é, o assistente social está submetido aos dilemas e limitações semelhantes aos dos trabaIhadores assalariados (condições objetivas e subjetivas do trabalho contemporâneo), vivenciando tais processos e seus desdobramentos no cotidiano profissional.

Ressalta-se que um importante desdobramento atual, ainda em discussão no Congresso Nacional nesse segundo semestre de 2016, mas que tende a comprometer decisivamente a viabilização de políticas sociais e a garantia de direitos, é a PEC 241, protagonizada pelo governo conservador e regressivo de Michel Temer. Essa PEC, que no presente vem mobilizando alguns setores da sociedade por meio de formas diversas de resistência (ocupação de escolas, paralizações de trabalhadores etc.), estabelece um teto para os gastos públicos: eles não podem crescer mais que a inflação (ou seja, crescimento real zero) por um prazo de 20 anos, a contar de 2017, com possibilidade de revisão somente após 10 anos, sendo que a Saúde e a Educação devem crescer pelo menos o equivalente à inflação, ou mais, desde que outras áreas sofram ainda mais cortes (BLUME, 2016).

No que se refere, ainda, ao momento contrarrevolucionário supracitado, Raichelis (2011, p. 752) acrescenta algumas dimensões, tais como: "o modo pelo qual o profissional incorpora na sua consciência o significado do seu trabalho, as representações que faz da profissão, a intencionalidade de suas ações, as justificativas que elabora para legitimar sua atividade". Esses elementos orientam a direção social e política do seu exercício profissional, e são tensionados pela conjuntura atual de exploração intensificada e precarizada do trabalho.

Portanto, vivemos um momento nada favorável à resistência coletiva, nos quais muitos trabalhadores (assistentes sociais ou não) encontram-se esgotados física e mentalmente, desorganizados, tomados por demandas que reconfiguram o conservadorismo ainda presente na profissão e, especialmente, nos espaços institucionais.

\footnotetext{
${ }_{18}$ Diante dos processos de adoecimento de assistentes sociais, Santos (2010) destaca problemas variados de coluna, gastrites, úlceras, depressões e síndromes as mais diversas como expressões de situações agudas de competividade, burocratismo e violação de direitos. "São processos de adoecimentos que nos colocam diante de situações de medo, pânico, desesperança quanto à possibilidade do futuro" (SANTOS, 2010, p. 703).
} 
Tempos de políticas sociais voltadas para o alívio da pobreza, mercantilização/privatização e assistencialização de políticas sociais (MOTA, 2009), ações do Estado direcionadas para a criminalização dos pobres e dos movimentos sociais ${ }^{19}$ (GUERRA, 2010), bem como ações diversas que não favorecem a reflexão crítica e acabam por desafiar tanto o exercício como a formação profissional em Serviço Social e, consequentemente, seu projeto ético-político e o processo de consciência crítica de seus agentes profissionais.

Mota (2009) argumenta, ainda, que está em curso uma tendência associada de privatização e assistencialização da proteção social no Brasil. Isso porque, ao mesmo tempo em que cresce a mercantilização/privatização das políticas sociais, a assistência social se amplia, "transformando-se num novo fetiche de enfrentamento à desigualdade social, na medida em que se transforma no principal mecanismo de proteção social no Brasil" (MOTA, 2009 , p. 134), direcionado para os mais pobres e se descolando da efetivação das outras políticas sociais. Por isso, de forma gradativa, os assistentes sociais vêm sendo cada vez mais requisitados a atuarem em políticas de alívio à pobreza (como exemplo típico temos o Programa Bolsa Família), concessão de benefícios pontuais, em detrimento da viabilização de direitos sociais.

Dentre essas ações diversas que não favorecem a reflexão crítica, um exemplo interessante é o projeto "Escola sem Partido" (PLS 193/2016, PL 1411/2015 e PL 867/2015). Esse projeto visa eliminar a chamada discussão ideológica no ambiente escolar, restringindo os conteúdos de ensino a partir de uma pretensa ideia de neutralidade do conhecimento. Na avalição das educadoras Dutra e Moreno (2016, n.p.),

trata-se de uma elaboração que contraria o princípio constitucional do pluralismo de ideias e de concepções pedagógicas, assim como o da liberdade de aprender, ensinar, pesquisar e divulgar o pensamento, a arte e o saber, considerando como válidos determinados conteúdos que servem à manutenção do status quo e como doutrinários aqueles que representam uma visão crítica.

Em suma, diante das tendências regressivas atuais, no campo da formação os desafios são inúmeros. Um exemplo é a exigência de um perfil profissional cada vez mais direcionado para habilidades e competências voltadas para a lógica do mercado, sendo capaz de ser mais competitivo e, ao mesmo passo, adaptar-se às alterações de seu tempo, respondendo de forma imediata e sem reflexão às demandas (im)postas pelos empregadores. Dessa forma, exige-se uma formação aligeirada (tais quais vemos nos cursos privados a distância em expansão no país) e direcionada para um mercado de trabalho em sintonia com o movimento capitalista de recuperação das

\footnotetext{
${ }^{19}$ Haja vista a ênfase presente na repressão à política de segurança pública nacional, com inúmeros exemplos cotidianos na mídia (e, principalmente, fora dela) de violência policial nas comunidades.
} 


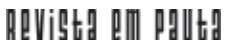

\} NOTAS SOBRE O PROJETO ÉTICO-POLÍTICO PROFISSIONAL - DUARTE, J. L. N. \}

DOI $10.12957 /$ REP.2017.30382

taxas de lucro, compatível com a agenda dos organismos internacionais. Nesta perspectiva, é necessário ampliar vagas no Ensino Superior em quantidade, e não em qualidade.

Com a contrarreforma do Estado, o Ensino Superior passa a ocupar o âmbito dos "serviços não exclusivos do Estado", sendo incorporado não como direito social, mas como serviço que pode ser controlado e administrado pelo mercado, com participação estatal mínima ou no básico. O próprio Censo da Educação Superior de 2013 (BRASIL/MEC/INEP, 2015) confirma a hegemonia do setor privado na condução dos cursos de graduação no Brasil e avalia que, nos últimos quatro anos (a partir de 2013), "o crescimento (das matrículas) na categoria pública está numa curva descendente, ao passo que o crescimento da rede privada se mantém estável e positivo" (BRASIL, 2015, p. 21), acarretando sérios rebatimentos para a qualidade da Educação Superior, em especial para a articulação entre ensino, pesquisa e extensão.

Conforme Guerra (2010, p. 724):

Prioriza-se a formação que atenda as orientações do Banco Mundial, sendo que democratizar passa a ser sinônimo de uma inserção, ainda que precarizada, em instituições de ensino, seja pública ou privada ${ }^{20}$, daí ser a expansão de vagas a meta cobrada pelos organismos internacionais.

Os desdobramentos da contrarreforma da Educação Superior e da sua lógica expansiva direcionada para os interesses do mercado incide e desafia de maneira indelével a formação profissional dos assistentes sociais, principalmente quanto à implementação das Diretrizes Curriculares para o Curso de Serviço Social de 1996. Dessa forma, causa impactos, por sua vez, no projeto ético-político profissional do Serviço Social brasileiro.

Em texto recentemente publicado (DUARTE, 2016), discutimos a questão da Educação Superior, o projeto de formação profissional do Serviço Social e as disputas atuais que o envolvem. Nesse texto, refletimos sobre as tensões presentes nas diretrizes curriculares aprovadas coletivamente pelo Serviço Social brasileiro, por meio da Abepss, em 1996, e a aprovação formal das diretrizes pelo Ministério da Educação (MEC), que só ocorreu em 2001, contando com importantes supressões do texto original discutido pela categoria profissional. Ainda que nesse momento não seja possível aprofundar esse debate, podemos afirmar que impasses e disputas envolvem esses distintos projetos de formação profissional dos assistentes sociais, fundados nas "diretrizes da Abepss" e nas "diretrizes do MEC", dificultando a

\footnotetext{
${ }^{20}$ No âmbito privado, temos a expansão de cursos no formato EAD de Norte a Sul do país. Já no caso da rede pública, em especial na década anterior (agora em processo de estagnação), ganha destaque a expansão/interiorização de cursos por meio do Programa de Reestruturação e Expansão das Universidades Federais (ReUni), mas sem as mínimas condições de estrutura física e corpo docente suficiente.
} 


\section{hevistg an pgutt}

\} NOTAS SOBRE O PROJETO ÉTICO-POLÍTICO PROFISSIONAL - DUARTE, J. L. N. \}

DOI 10.12957/REP.2017.30382

viabilização de uma "formação (crítica) que seja capaz de incidir (plenamente) sobre as consciências dos futuros profissionais, confrontando-se com a alienação presente na vida cotidiana" (ORTIZ, 2013, p. 18).

Por fim, podemos dizer que o conjunto de determinações objetivas e subjetivas que tece o modo de ser e viver da classe trabalhadora, particularmente do trabalhador assistente social: 1) condiciona a possibilidade ou não de realização de finalidades e resultados projetados; e 2) espraia-se de forma ostensiva e com muitas faces, fazendo parte de uma mesma racionalidade que se expressa e condiciona tanto o exercício quanto a formação profissional em Serviço Social.

Portanto, articulando tais questões com os fundamentos de um projeto, podemos afirmar que o projeto ético-político, enquanto projeto coletivo profissional (expressão do confronto entre teleologia e causalidade), encontra limites (em particular, no presente): 1) de natureza estrutural, pois tem limites em face da sociedade capitalista alienada e reificada; e 2) dificuldades de natureza conjuntural, que agudizam os limites de ordem estrutural, tais como as transformações societárias contemporâneas que incidem sobre a vida social e sobre a profissão, constituindo-se como obstáculos concretos ao horizonte transformador de sociedade e crítico de profissão (aspectos importantes do projeto ético-político).

Diante desse conjunto complexo, é imprescindível o enfrentamento firme, a partir do reconhecimento dos limites e contradições como condição essencial para o desenvolvimento de todas as potencialidades de um projeto profissional crítico, que ilumina e dá a direção em tempos de retrocessos para a classe trabalhadora em geral e, em particular, para o Serviço Social. A categoria profissional, devido à sua herança histórico-política e sendo fruto do processo de renovação, vem resistindo (não sem dificuldades) com ações na contramão da conjuntura de reestruturação do capital e contrarreforma do Estado brasileiro, em especial protagonizada pelo coletivo profissional por meio das entidades organizativas da categoria, bem com seu vínculo com outros espaços de luta, como os movimentos sociais.

No entanto, é oportuno considerar que o processo de resistência não se constitui como um movimento linear, mas dinâmico, contraditório, marcado por avanços e recuos, conquistas e derrotas, "entendidas numa relação dialética que favorece, potencializa e oxigena nosso movimento de aprender e atuar profissional e politicamente nas contradições e de seguir adiante qualitativamente melhor" (SANTOS, 2010, p. 704 - grifos nossos).

Desse modo, os assistentes sociais, seja em seu cotidiano profissional (parcela relevante de profissionais que, mesmo em condições adversas, mobilizam ações ousadas e afinadas aos interesses dos trabalhadores), e/ou por meio das entidades organizativas da profissão, têm o papel de fortalecer, de forma criativa e corajosa, a luta e o processo de resistência do Serviço Social e fora dele (luta mais geral da classe trabalhadora). Nesses termos, é necessário e urgente recuperar fôlego diário para a identificação e 


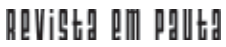

\} NOTAS SOBRE O PROJETO ÉTICO-POLITICO PROFISSIONAL - DUARTE, J. L. N. \}

DOI 10.12957/REP.2017.30382

o desenvolvimento de potencialidades do projeto ético-político crítico do Serviço Social que ainda estejam adormecidas.

Assim, o projeto ético-político constitui-se não como uma impossibilidade, mas como um desafio cotidiano, pois "[...] o que se apresenta como obstáculo é apenas a casca do impossível, que encobre as possibilidades de os homens construírem sua própria história" (IAMAMOTO, 2007, p. 208). De fato, tal projeto crítico, fruto de um Serviço Social renovado após os anos de 1980, tem limites e convive com o aspecto da pluralidade. No entanto, ao mesmo tempo, alimenta-se da realidade e passeia no campo da contradição presente nos desafios e entraves do exercício e da formação da profissão, estimulando parcela importante da categoria a criar e recriar estratégias e possibilidades para fazer história.

É necessário não só manter essa chama, mas também intensificála! Por isso, para que possamos acionar todas as potencialidades do projeto ético-político, faz-se essencial investir, a partir do suporte teórico-metodológico da tradição marxista: a) no conhecimento profundo do movimento da sociedade e das tensões que permeiam a formação e o exercício profissional, em articulação com os desafios atuais (im)postos à classe trabaIhadora; e b) na intensificação da organização ético-política dos profissionais de Serviço Social, bem como na atuação em diversos espaços de mobilização (entidades representativas da categoria e tantos outros movimentos), condensando forças na direção de uma agenda coletiva de lutas. Esse conjunto exige de todos nós um rigor crítico, sem ilusões, para além das aparências, pois "sem o efetivo conhecimento do real, a atualização do fim é uma impossibilidade" (LESSA, 2002, p. 92).

Aos defensores do projeto ético-político brasileiro, em especial diante das disputas atuais e da necessidade de fortalecimento do seu caráter crítico (em território nacional e para além dele), afirmamos: é necessário manter a visão cristalina sobre o presente, buscar na indignação e na inquietação cotidiana estratégias para ousar e firmar compromissos, numa perspectiva de reinvenção do presente e de um futuro que parece distante, buscando encontrar "na boca da noite um gosto de sol" (NASCIMENTO, 1972). 


\section{Referências}

ABRAMIDES, M. B.; CABRAL, M. S. A organização política do Serviço Social e o papel da Ceneas/Anas na virada do Serviço Social brasileiro. In: CONSELHO FEDERAL DE SERVIÇO SOCIAL (CFESS) (Org.). 30 anos do Congresso da Virada. Brasília: CFESS, 2009.

BLUME, B. A. Como funciona o teto de gastos público? 2016. Disponível em: <http://www.politize.com.br/teto-de-gastos-publicos-infografico/>. Acesso em: 22 nov. 2016.

BRASIL. Lei $n^{\circ} 12.317$, de 26 de agosto de 2010. Acrescenta dispositivo à Lei $\mathrm{n}^{\circ}$ 8.662, de 7 de junho de 1993, para dispor sobre a duração do trabalho do assistente social. Brasília, 2010. Disponível em: <http://www.planalto. gov.br/ccivil_03/_Ato2007-2010/2010/Lei/L12317.htm>. Acesso em: 12 jun. 2015.

BRASIL/MEC/INEP. Censo da Educação Superior 2013 - Resumo técnico. Brasília: Inep, 2015. Disponível em: <http://download.inep.gov.br/download/ superior/censo/2013/resumo_tecnico_censo_educacao_superior_2013. pdf>. Acesso em: 2 maio de 2016.

CFESS. Código de ética profissional. In: Coletânea de leis. Natal: Cress, 2003. DUARTE, J. L. N. Educação Superior e projeto de formação profissional: disputas e desafios para o Serviço Social brasileiro. In: XV CONGRESSO BRASILEIRO DE SERVIÇO SOCIÁL. Anais... Recife, 2016.

DUTRA, C.; MORENO, C. Escola sem partido: estratégia golpista para calar a educação. Carta Capital, São Paulo, 2016. Disponível em: <http://www. cartacapital.com.br/educacao/escola-sem-partido-estrategia-golpista-paracalar-a-educacao>. Acesso em: 23 nov. 2016.

GUERRA, Y. Formação profissional frente aos desafios da intervenção e das atuais configurações do ensino público, privado e a distância. Serviço Social e Sociedade, São Paulo: Cortez, n. 104, 2010.

GUERRA, Y; ORTIZ, F. G. Os caminhos e os frutos da "Virada": apontamentos sobre o III Congresso Brasileiro de Assistentes Sociais. Revista Praia Vermelha, v. 19, n. 2, PPGSS/Escola de Serviço Social/UFRJ, 2009.

IAMAMOTO, M. V. O Serviço Social em tempos de capital fetiche: capital financeiro, trabalho e questão social. São Paulo: Cortez Editora, 2007.

IASI, M. L. Ensaios sobre consciência e emancipação. São Paulo: Expressão Popular, 2011.

LESSA, S. Teleologia, causalidade e objetivação. In: Mundo dos Homens: trabalho e ser social. São Paulo: Boitempo Editorial, 2002. 


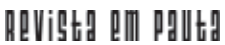

\} NOTAS SOBRE O PROJETO ÉTICO-POLÍTICO PROFISSIONAL - DUARTE, J. L. N. \}

DOI 10.12957/REP.2017.30382

MARX, K. O capital: crítica da economia política. Livro primeiro. São Paulo: Nova cultural, 1985.

2004.

. Manuscritos econômico-filosóficos. São Paulo: Boitempo Editorial,

MARX, K.; ENGELS, F. A ideologia alemã. São Paulo: Expressão Popular, 2009.

MÉSZÁROS, I. A teoria da alienação em Marx. São Paulo: Boitempo editorial, 2006.

MOTA, A. E. A centralidade da assistência social na Seguridade Social brasileira nos anos 2000. In: O mito da assistência Social: ensaios sobre Estado, política e sociedade. São Paulo: Cortez, 2009.

NASCIMENTO, M. Nada será como antes. In: Clube da Esquina. Belo Horizonte, EMI, 1972.

NETTO, J. P. Capitalismo e reificação. São Paulo: Livraria Editora Ciências Humanas, 1981.

. Ditadura e Serviço Social - uma análise do Serviço Social no Brasil pós-1964. São Paulo: Cortez, 1998.

A Reconceituação: ainda viva, 40 anos depois. In: ALAYÓN, N. (Org.). Trabajo social latinoamericano: a 40 años de la Reconceptualización. Argentina: Espacio Editorial: 2005.

. Para a crítica da vida cotidiana. In: NETTO, J. P.; CARVALHO, M. C. B. Cotidiano: conhecimento e crítica. São Paulo: Cortez, 2007.

A construção do projeto ético-político do Serviço Social. In: MOTA, A. E. et al. (Org.). Serviço Social e saúde: formação e trabalho profissional. São Paulo: Cortez, 2008.

ORTIZ, F. G. O Serviço Social no Brasil: os fundamentos de sua imagem social e da autoimagem de seus agentes. Rio de Janeiro: E-Papers/Faperj, 2010.

. Notas sobre as diretrizes curriculares: avanços, impasses e desafios. In: GUERRA, Y.; LEITE, J. L.; ORTIZ, F. G. (Org.). Temas contemporâneos: o Serviço Social em foco. São Paulo: Outras Expressões, 2013.

RAICHELIS, R. O assistente social como trabalhador assalariado: desafios frente às violações de seus direitos. Serviço Social e Sociedade, São Paulo: Cortez, n. 107, 2011.

SANTOS, S. M. de M. dos. O CFESS na defesa das condições de trabalho e do projeto ético-político profissional. Serviço Social e Sociedade, São Paulo: Cortez, n. 104, 2010. 


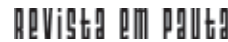

I NOTAS SOBRE O PROJETO ÉTICO-POLITICO PROFISSIONAL - DUARTE, J. L. N.

DOI 10.12957/REP.2017.30382

Recebido em 17 de fevereiro de 2016.

Aprovado para publicação em 09 de novembro de 2016. DOI 10.12957/rep.2017.30382

\section{(c) (1)}

A Revista Em Pauta: Teoria Social e Realidade Contemporânea está licenciada com uma Licença Creative Commons Atribuição 4.0 Internacional.

EM PAUTA, Rio de Janeiro - $1^{\circ}$ Semestre de 2017 - n. 39, v. 15, p. 176 - 200 